\title{
Extreme flood estimations on a small alpine catchment in Switzerland, the case study of Limmerboden
}

\author{
F. Zeimetz ${ }^{1}$, J. García-Hernández ${ }^{2}$, and A. J. Schleiss ${ }^{1}$ \\ ${ }^{1}$ Ecole Polytechnique Fédérale de Lausanne, Lausanne, Switzerland \\ ${ }^{2}$ Centre de Recherche sur l'Environnement Alpin, Sion, Switzerland \\ Correspondence to: F. Zeimetz (franz.zeimetz@epfl.ch)
}

Received: 11 March 2015 - Accepted: 11 March 2015 - Published: 11 June 2015

\begin{abstract}
In this paper, a case study on the estimations of extreme floods is described. The watershed chosen for the analysis is the catchment of the Limmernboden dam situated in Switzerland. Statistical methods and the simulation based "Probable Maximum Precipitation - Probable maximum Flood" (PMP-PMF) approach are applied for the estimation of the safety flood according to the Swiss flood directives. The results of both approaches are compared in order to determine the discrepancies between them. It can be outlined that the PMPPMF method does not always overestimate the flood.
\end{abstract}

\section{Introduction}

In Switzerland, 160 large dams $(h>15 \mathrm{~m}$ according to the definition adopted by the International Commission on Large Dams) have been constructed in the past. This roughly corresponds to 20 dams per $5000 \mathrm{~km}^{2}$. In comparison to the European leading hydroelectricity producer, Norway, the large dam density is approximately 4 dams per $5000 \mathrm{~km}^{2}$. In China, the world leading hydroelectricity producer, the dam density raises to $11.5 \mathrm{dams}$ per $5000 \mathrm{~km}^{2}$. Due to the high dam density in Switzerland, flood safety is a critical topic for Swiss engineers and the Swiss Federal Office of Energy already initiated research projects on extreme flood issues some twenty years ago. In the context of this vast still ongoing issue, the project Cruex ++ started in 2012 within the goal of improving extreme flood estimations in alpine catchments.

In Switzerland, dam safety guidelines prescribe the estimation of the so called design flood, $Q_{1000}$, and the safety flood, estimated by $1.5 \cdot Q_{1000}$ or the PMF for dam design (SFOE, 2008). The design flood $Q_{1000}$ has to be evacuated below the maximum operation level, even if the spillway with the highest capacity is out of order (" $n-1$ rule"). Concerning the safety flood, the dam has to withstand it without failure; all spillways being assumed as operational for concrete dams whereas the " $n-1$ rule" is applied to embankment dams. In this framework, a case study on extreme flood estimations for the small Swiss alpine catchment, Limmernboden, with a large arch dam, is performed.

\section{The Limmernboden catchment}

The Limmernboden catchment is located in the northern part of the Swiss Alps in the canton of Glarus. A detailed representation of the main catchment (with an area of $17.8 \mathrm{~km}^{2}$ ), the glacier cover $\left(17.5 \mathrm{~km}^{2}\right)$, the lake and the additional catchment area $\left(31.8 \mathrm{~km}^{2}\right)$ due to 7 lateral intakes is shown on Fig. 1. The altitude range of the main catchment varies from $1858 \mathrm{~m}$ a.s.l. at lake level up to $3419 \mathrm{~m}$ a.s.l. and from 1927 up to $3614 \mathrm{~m}$ a.s.l. for the additional catchment. The total capacity of the lateral intakes is limited to $10.5 \mathrm{~m}^{3} \mathrm{~s}^{-1}$. The spillway capacity of the Limmernboden arc dam is $89 \mathrm{~m}^{3} \mathrm{~s}^{-1}$. The hydrogeological map of Switzerland (SwissTopo, 2007) indicates a karstic behaviour (and the presence of losses) of the catchment.

\section{The data}

Meteorological and discharge date have been utilized for the analysis presented in this paper.

The classical statistical methods using mathematical distributions to extrapolate the measured data to extreme events only need discharge data. However, statistical methods like 


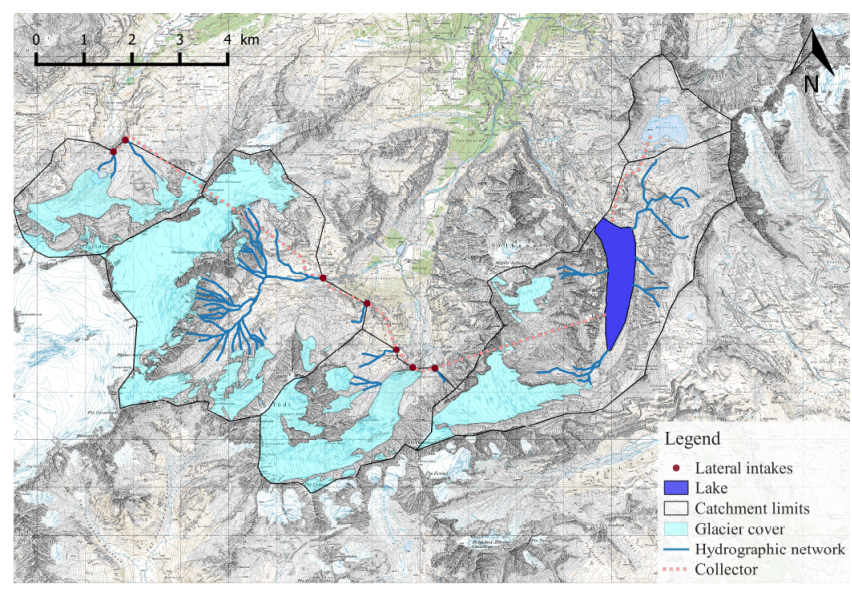

Figure 1. The main catchment of the Limmernboden dam with the additional catchment limited by lateral intakes and its glacier cover.

the Gradex (Duband and Guillot, 1967) also refer to precipitation data for the estimation of extreme discharges (cf. Sect. 4.3).

The simple rainfall-runoff methods only need precipitation as inputs, but the more complex rainfall-runoff methods need precipitation and temperature as inputs for the simulations. Discharge data are required for the calibration of the rainfall-runoff model. A more detailed explanation of the here used rainfall-runoff model is outlined in Sect. 5.

\subsection{Meteorological data}

The meteorological data is provided by MeteoSwiss. For the present analysis, 10 meteorological stations have been taken into account (Fig. 2); all stations measuring precipitation but only 4 measuring temperature. The data are available for the period from 1 January 1981 to 31 December 2009 and have been considered with an hourly time resolution.

\subsection{Discharge data}

The discharge data is provided by the dam operator Kraftwerke Linth-Limmern AG (KLL) with a daily time resolution. The data are actually based on water level measurements in the lake and are converted by the operator in discharge values. The covered period goes from 1 October 1997 to 31 March 2013.

\section{Statistical flood estimations}

Extreme flood estimations using statistical methods are performed using the annual maxima method, the peak over threshold method (POT), described by Coles (2001), and the GRADEX method (Duband and Guillot, 1967). The three methods as well as their application are explained below. The results are summarized on the graph of Fig. 3.

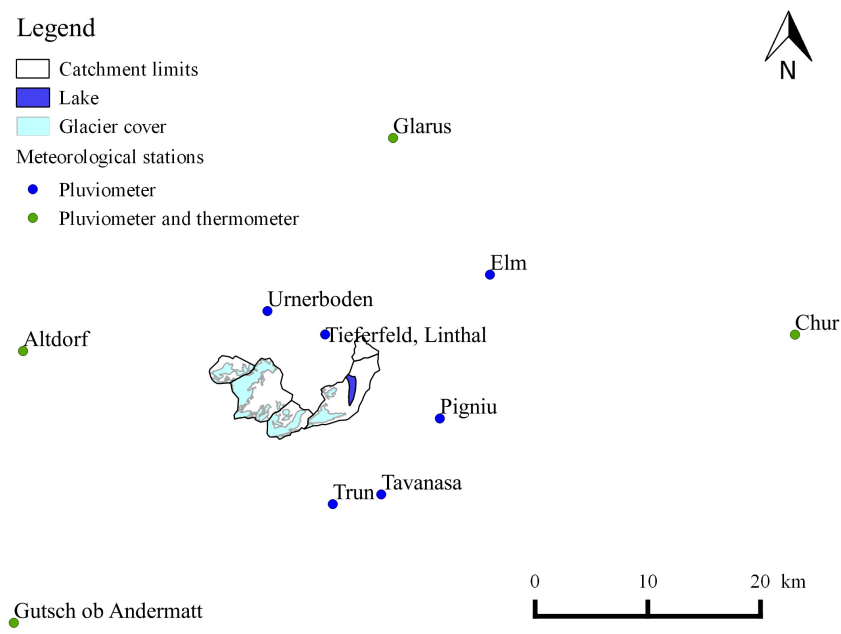

Figure 2. Situation of the meteorological stations around the Limmernboden catchment used for the calibration and validation of the hydrological model.

\subsection{Annual maxima method}

The annual maxima method, described by Coles (2001), requires the highest measured discharge value for each year. The data series subjected to the statistical analysis must be continuous, meaning that it must contain one maximum value per year. No lack is tolerated. Coles (2001) proposes to use the general extreme value distribution (GEV) for the extrapolation.

For this analysis, the GEV distribution is fitted to the annual maxima series using the maximum likelihood method.

The fitted GEV and the corresponding $95 \%$ confidence interval are shown on Fig. 3.

\subsection{Peak over threshold (POT) method}

The peak over threshold method takes not only into account the annual maxima but the entire data set $X=$ $\left\{x_{1}, x_{2}, \ldots x_{i}, \ldots x_{n}\right\}$ that is then subjected to an analysis of its statistical behaviour in order to determine a threshold $u$ beyond which the behaviour of the remaining data $(X>u)$ set can be qualified as extreme. Coles (2001) advises to fit the general Pareto distribution to model exceedances of a threshold $u$ (Eq. 1). The shape parameter $\xi$ and the scale parameter $\sigma$ are estimated with the maximum likelihood method.

$P\{X>x \mid X>u\}=\left[1+\xi\left(\frac{x-u}{\sigma}\right)\right]^{-1 / \xi}$

The POT method allows fitting the distribution to a larger number of values, which results in smaller confidence intervals compared to the results of the annual maxima method. Therefore, the POT method reveals to be very useful in the case of short data sets. 


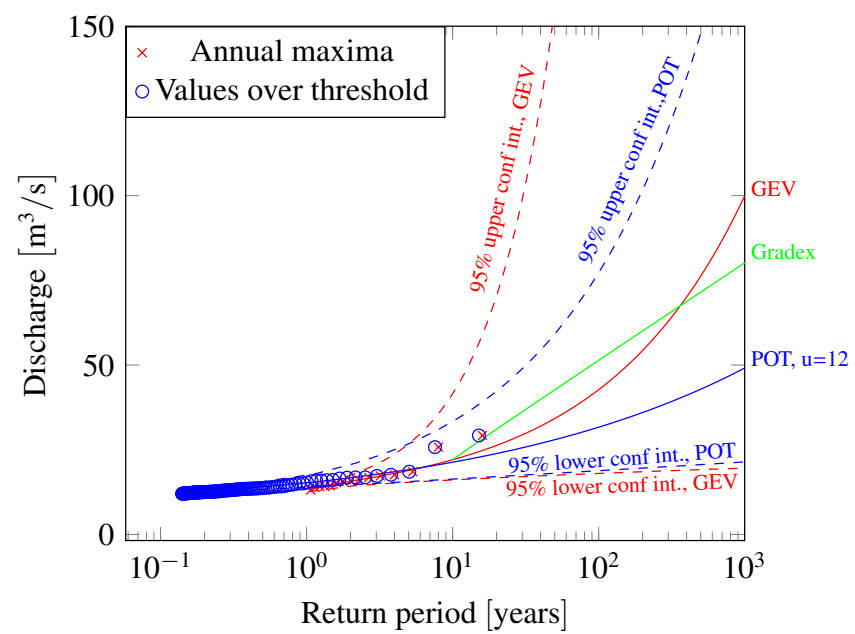

Figure 3. Extrapolation of the discharge data with the annual maxima method using the GEV distribution, the POT method and the Gradex method.

The threshold is chosen using a mean excess plot and is then validated using graphs plotting a certain range of thresholds against the parameter estimates of the modified scale parameter $\sigma^{*}$ (Eq. 2) and the shape parameter $\xi$ with the related $95 \%$ confidence interval as exposed by Coles (2001).

$\sigma^{*}=\sigma-\xi u$

Figures 4, 5 and 6 let conclude that the choice of the threshold $u=12 \mathrm{~m}^{3} \mathrm{~s}^{-1}$ is reasonable. The fit to the exceedances defined by this threshold is shown on Fig. 3 .

\subsection{GRADEX method}

The concept of the GRADEX method (Duband and Guillot, 1967) is to assume the saturation of the soil at a certain moment, normally assigned to a 10 -year return period flood. From this point on, the entire precipitation will runoff, resulting in a breaking point on the plot of the extrapolation as shown on Fig. 3. The assumption of saturation induces the substitution of the discharge distribution by the rainfall distribution for return periods higher than the chosen breaking point. Hence, the GRADEX method requires a statistical analysis of both the discharge and the precipitation data.

The rainfall data is fitted by a Gumbel distribution as proposed by Duband and Guillot (1967). It is important to mention that this method does not take into account the karstic behaviour of the catchment as the discharge extrapolation (Fig. 3) is based on precipitation data.

\section{Rainfall-runoff simulations}

The rainfall-runoff simulations are performed with a semidistributed conceptual hydrological model. The catchment is subdivided in so called altitude bands that are assumed to

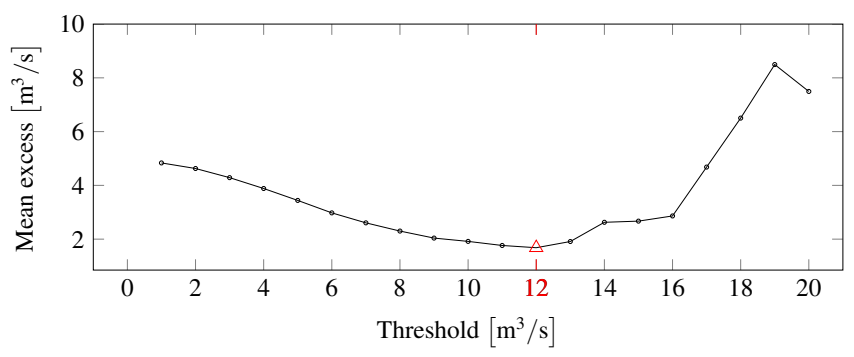

Figure 4. Mean excess versus threshold, with the chosen threshold shown in red.

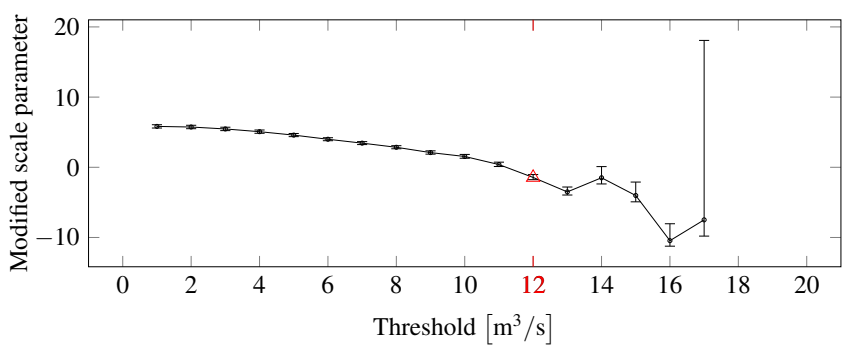

Figure 5. Modified scale parameter versus threshold, with the chosen threshold shown in red.

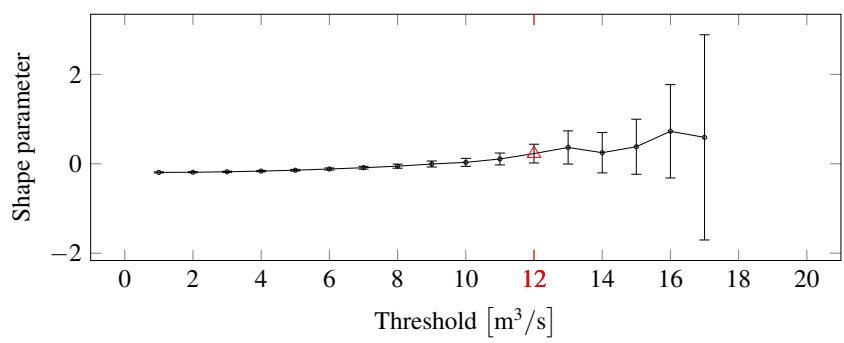

Figure 6. Shape parameter versus threshold, with the chosen threshold shown in red.

be hydrologically homogeneous. A modified version of the model GSM-SOCONT (Jordan et al., 2012) is used for this study. This model is composed of two sub-models, the modified GSM model for the glacier altitude bands and the modified SOCONT model for the non-glacier altitude bands. The here used GSM-SOCONT model allows to simulate the hydrological behaviour in terms of surface runoff, soil infiltration, subsurface flow, karstic losses, snow melt and glacier melt.

The model needs temperature and rainfall data as input. The potential evapotranspiration is estimated by the Turc model (Turc, 1961). 


\subsection{Calibration and validation}

The entire discharge data set has been subdivided into two periods of 6 hydrological years. The calibration period starts on 1 October 1997 and ends on 1 October 2003. Thus, the validation period consists in the remaining data set going from 1 October 2003 to 1 October 2009. Figure 7 shows the first period with the comparison between the simulations using the calibrated model and the measured discharge data. The Nash-Sutcliff performance coefficient of $\mathrm{NS}=0.88$ indicates a very good calibration according to Moriasi et al. (2007). The volume ratio VR $=1.03$ confirms the goodness of the simulation results. The reliability of the model can be validated by the performance coefficients estimated for the validation period ( $\mathrm{NS}=0.90, \mathrm{VR}=1.04$ ). The comparison between the simulation results and the measured discharge over the validation period is shown on Fig. 8.

Due to missing measurements of karstic losses, and under the assumption that the inputs (meteorological data) are accurate, the present karstic behaviour has been modelled by a losses function with an upper discharge limit, determined during the calibration process at the same time than the other hydrological parameters. The simulated discharge is the sum of different hydrological processes separately calibrated, i.e. snow melt, glacier melt, infiltration, runoff. These processes are reasonably represented by the model. Due to the good model performance, in terms of Nash coefficient and volume ratio, in combination with reasonable partial hydrological processes, equifinality can be assumed very small and has therefore not been considered for further analysis.

\subsection{Extreme flood estimation with the PMP-PMF method}

The PMP-PMF method aims the estimation of the probable maximum flood (PMF) by routing the probable maximum precipitation (PMP) through hydrological simulations. The PMP is defined by WMO (2009) as "the theoretical maximum precipitation for a given duration under modern meteorological conditions". WMO (2009) refers to the PMF as "the theoretical maximum flood that poses extremely serious threats to the flood control of a given project over a design watershed".

In Switzerland, PMP maps have been elaborated for three different wind directions, north, south and west-north-west (Hertig et al., 2005). These maps also differ depending on the duration of the storm. Thus for every considered wind direction a set of maps considering different storm durations $(1,3,6,9,12$ and $24 \mathrm{~h})$ is available. However, the $1 \mathrm{~h}$-maps seem to generally overestimate the storm events, therefore it is not considered for this study.

Furthermore, Receanu (2013) developed a model for a spatio-temporal distribution of precipitation heights. This model, called maximum precipitation flood (MPF), has been used to distribute the PMP data with a 10 min time step.

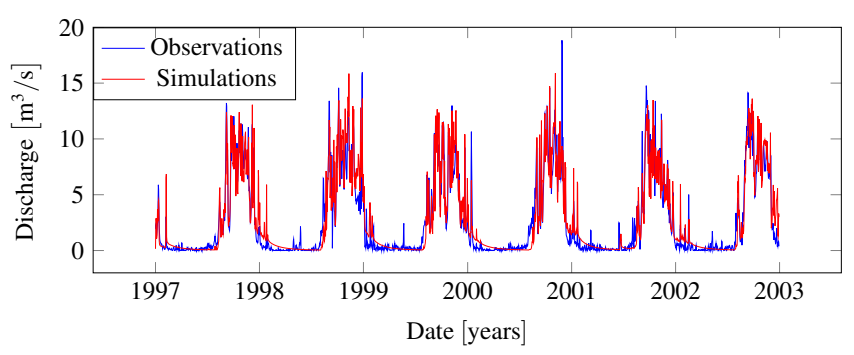

Figure 7. Simulation results compared to the observations for the calibration period from 1 October 1997 to 1 October 2003.

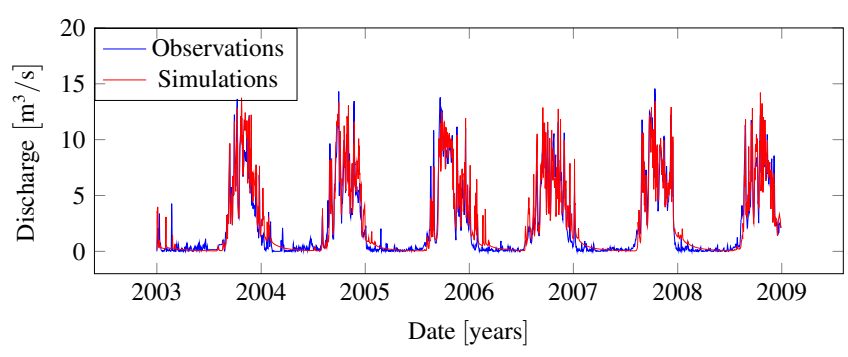

Figure 8. Simulation results compared to the observations for the validation period from 1 October 2003 to 1 October 2009.

The PMF is derived using the calibrated hydrological model previously described. This hydrological model needs to be initialized in terms of initial soil moisture and initial snow height. During the calibration/validation simulations, the model records the evolution of the state variables (snow height, soil saturation). Thus, the initial conditions for the PMP-PMF simulation can be extracted from the previous calibration/validation simulations at any moment in time within the time resolution of the performed simulation.

For this case study, the assumption that initial conditions observed before a major flood can be considered as realistic conditions for the PMP-PMF simulation has been made. The calculation is performed with a 10 min time step and saved with an hourly time step. Figure 9 shows the hyetograph and the corresponding discharge of the flood as well as the moment of the initial conditions choice (grey dot).

Some additional assumptions were made for the PMF estimation. Concerning the MPF model for providing the spatiotemporally structured precipitation data, it has been validated during a $6 \mathrm{~h}$ storm (Receanu, 2013) and can be considered validated for shorter storm durations. For thus durations, a concatenation of short storm structures was performed in order to stay in the validated conditions of the MPF model. Rainfalls longer than $6 \mathrm{~h}$ are composed by 3 and $6 \mathrm{~h}$ spatiotemporal structures. The volume of the resulting event is then adapted to the volume indicated by the PMP map corresponding to the final PMP duration. The list of the structures generated for this study is not exhaustive due to the number of degrees of freedom existing in the MPF model. Since 


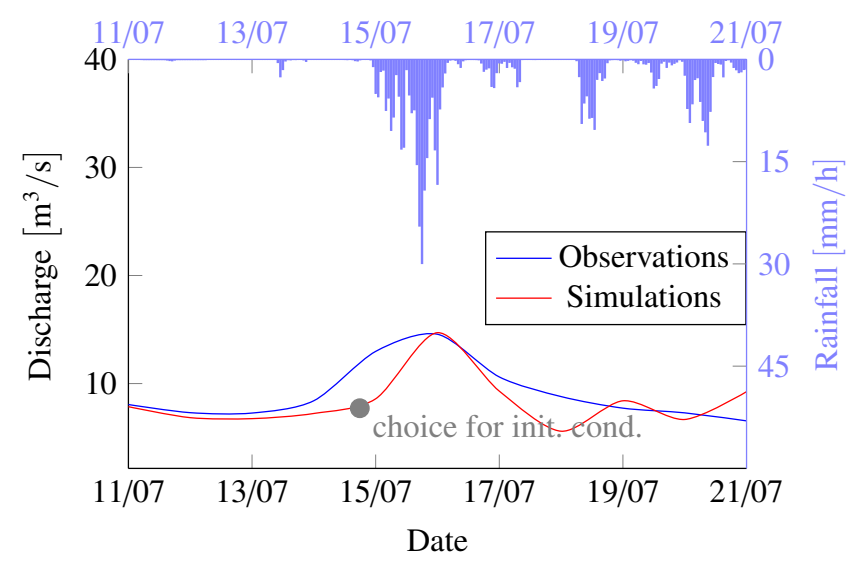

Figure 9. Simulation results compared to the observations for the period from 1 July to 31 July 2001 with indication of the moment for the chosen initial conditions for the PMP-PMF simulation.

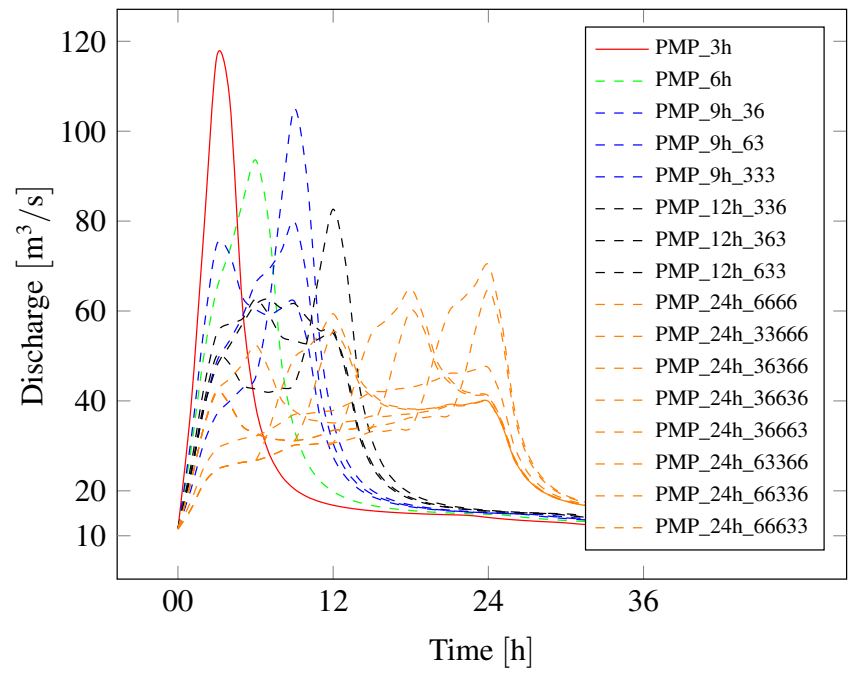

Figure 10. PMF estimations for different durations of PMP with different spatio-temporal rainfall structures. The legend of the graph indicates the composition of the structure by shorter rainfall events (PMP_9h_36 is a 9h PMP composed by a 3 and $6 \mathrm{~h}$ PMP structure).

a choice has been realized for the spatio-temporal precipitation data, the resulting discharges are not exhaustive either. However, the choices have been wisely made in collaboration with a meteorologist. Detailing the arguments for the taken choices would go too far for this paper. A more exhaustive list would lead to more nuanced hydrographs but would not change the range of the results.

The results of the PMP-PMF simulations are shown on Fig. 10. It can be deduced from this graph that the critical storm duration for the Limmerboden basin is smaller than $6 \mathrm{~h}$. As the only available PMP data with storm duration below $6 \mathrm{~h}$ is the $3 \mathrm{~h}$-PMP, it is assumed that the critical precipitation duration is $3 \mathrm{~h}$.

\section{Comparisons and discussion}

In this section, the statistically estimated safety floods ( $\left.Q_{\text {stat }}=1.5 \cdot Q_{1000}\right)$ are compared to the PMF estimations ( $\left.Q_{\mathrm{PMF}}\right)$. The comparison is undertaken by the intermediate of the ratio $R$ between $Q_{\mathrm{PMF}}$ and $Q_{\text {stat }}$ defined by Eq. (3).

$R=\frac{Q_{\mathrm{PMF}}}{Q_{\text {stat }}}$

The comparison is made for the $3 \mathrm{~h}$-PMF discharge $Q_{\mathrm{PMF}, 3 \mathrm{~h}}$. The statistical flood estimations from the extrapolation of daily values have to be converted to hourly peak discharges in order to compare both approaches. The simulation over the whole period from 1997 to 2009 allowed determining that the hourly flood estimations are on average 1.7 times higher than the daily mean flood discharge. The statistical values used for the comparison are converted to daily peak discharges by multiplying them by the factor 1.7 . The resulting values of the ratio $R$ are presented in Table 1 . The results indicate an overestimation by the statistical flood estimations compared to the PMF.

This can be due to different reasons. The list of the tested PMP events misses shorter storms due to the non-existence of PMP maps corresponding to short durations between 1 and $6 \mathrm{~h}$ other than $3 \mathrm{~h}$. Thus the real critical storm duration could be different from $3 \mathrm{~h}$. Considering the GEV estimation, a reason for the high difference could be the small amount of discharge observations available for the extrapolations. Hence, the extrapolation to high return periods can be highly biased by the available series. This assumption can be fortified by the fact that the estimation with the POT method, involving a lot more data are closer to the PMF estimations, as well as the Gradex method, based on a time series (precipitation) that is about 5 times longer than the discharge time series.

These results also show the differences between the simulation and statistical methods that should logically approach asymptotically the PMF value. However, Fig. 3 shows that the extrapolations are described by monotonously increasing functions that are not approaching an upper discharge limit. Among the statistical methods, the most logical statistical estimation is obtained with the POT method; and the $3 \mathrm{~h}-\mathrm{PMF}$ is very close to this statistical estimation.

Concerning the confidence intervals it should be mentioned that the short extrapolated time series lead to very large intervals that weaken the reliability of the statistical estimates and raise the importance of another method for extreme flood estimation. 
Table 1. Ratio $R$ between the simulated discharges of $Q_{\mathrm{PMF}}$ for $3 \mathrm{~h}$ and the statistical estimations of the safety flood converted to hourly peak flow values.

\begin{tabular}{cccc}
\hline$R$ & $Q_{\mathrm{GEV}}\left(1.5 \cdot Q_{1000}\right)=255 \mathrm{~m}^{3} \mathrm{~s}^{-1}$ & $Q_{\mathrm{POT}}\left(1.5 \cdot Q_{1000}\right)=126 \mathrm{~m}^{3} \mathrm{~s}^{-1}$ & $Q_{\mathrm{Gradex}}\left(1.5 \cdot Q_{1000}\right)=204 \mathrm{~m}^{3} \mathrm{~s}^{-1}$ \\
\hline$Q_{\mathrm{PMF}, 3 \mathrm{~h}}=116 \mathrm{~m}^{3} \mathrm{~s}^{-1}$ & 0.45 & 0.92 & 0.57 \\
\hline
\end{tabular}

\section{Conclusions}

Considering the definition of the PMF as outlined by WMO (2009) and cited in Sect. 5.2, the results of the discharge estimations seem mostly contradictory as the statistical methods return higher estimations than the PMP-PMF method. The here analysed small catchment of Limmernboden is a good example to show that the PMP-PMF method may not always overestimate extreme flood. Statistical methods can, in some cases, lead to very high estimates, up to more than two times higher than the estimated PMF value, what underlines the fact that statistical methods are really not advised for extreme flood estimations based on short time series, as already pointed out by DWA (2012). However, further analysis have to be undertaken in order to verify a possible flood underestimation of the here presented PMF value. This shows the importance of using both methods based on different concepts in order to compare the results and judge the estimates, especially when the available discharge time series is short and high return periods are aimed.

Acknowledgements. The research presented in this paper is funded by the Federal Office of Energy (OFEN) and is undertaken in collaboration with the engineering companies edric.ch, Hertig \& Lador SA as well as with the Centre de recherche sur l'environnement alpin CREALP. Furthermore, the author wants to thank the reviewer and the typesetter for the constructive remarks and their flexibility.

\section{References}

Coles, S.: An Introduction to Statistical Modeling of Extreme Values, in: Springer Series in Statistics, Springer-Verlag London, doi:10.1007/978-1-4471-3675-0, 2001.

Duband, D. and Guillot, P.: La méthode du Gradex pour le calcul de la probabilité des crues à partir des pluies, International Association of Hydrological Sciences Publications, 84, 560-569, 1967 (in French).

DWA: Merkblatt DWA-M 552, Ermittlung von Hochwasserwahrscheinlichkeiten, DWA, Dt. Vereinigung für Wasserwirtschaft, Abwasser u. Abfall, 2012 (in German).

Hertig, J.-A., Audouard, A., and Plancherel, A.: Cartes des précipitations extrêmes pour la Suisse (PMP 2005), Lausanne, Switzerland, 2005 (in French).

Jordan, F., Brauchli, T., Garcia Hernandez, J., Bieri, M., and Boillat, J. L.: RS 2012, Rainfall-Runoff Modelling, User guide, unpublished manual, e-dric.ch, Lausanne, 2012.

Moriasi, D. N., Arnold, J. G., Van Liew, M. W., Bingner, R. L., Harmel, R. D., and Veith, T. L.: Model Evaluation Guidelines for Systematic Quantification of Accuracy in Watershed Simulations, Transaction of the ASABE, 50, 885-900, 2007.

Receanu, R.: Simulation fine des précipitations et des crues extrêmes. Application aux petits bassins versants alpins non glaciaires, $\mathrm{PhD}$ thesis, Faculté des géosciences et de l'environnement, Université de Lausanne UNIL, 220 pp., 2013 (in French).

SFOE, S. F. O. o. E.: Documentation de base relative à l'élaboration de la sécurité en cas de crue, Swiss Federal Office of Energie, 26, 2008 (in French).

SwissTopo: Hydrogeological Map of Switzerland: Groundwater Resources 1:500 000 (Groundwater Resources 500), Federal Office of Topography swisstopo, 2007.

Turc, L.: Evaluation des besoins en eau d'irrigation, évapotranspiration potentielle, Ann. Agron., 12, 13-49, 1961 (in French).

WMO (World Meteorological Organization): Manual on Estimation of Probable Maximum Precipitation (PMP), WMO-No. 1045, Geneva, Switzerland, 2009. 